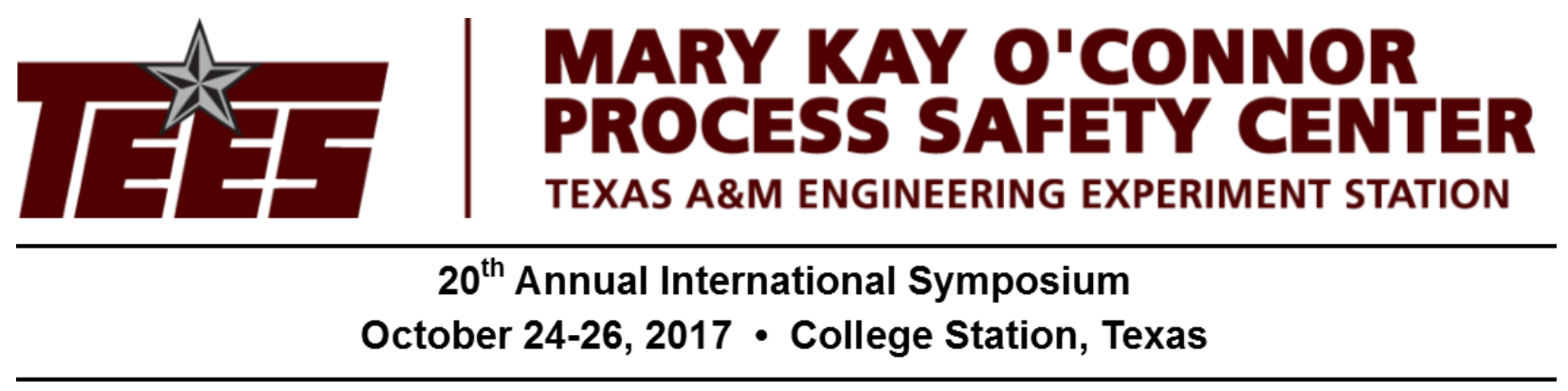

\title{
Modelling large LNG pool fires on water
}

\author{
Steven Betteridge \\ Shell Global Solutions (UK), \\ Brabazon House, Concord Business Park, \\ Manchester, M22 ORR, UK \\ Email: Steven.Betteridge@ shell.com
}

\begin{abstract}
There has been a rising demand for natural gas across the World. In many countries, this demand is being satisfied through an increasing number of marine LNG Carrier (LNGC) deliveries and hence there is a safety requirement to understand the consequences of significant accidents that could lead to the catastrophic failure resulting in a large spill of LNG in a harbor. The impact of thermal radiation on LNGCs, terminal facilities and the public outside the site fence-line from an LNG pool fire on water could extend a long distance according to current empirical models. The Phoenix pool fire experiments were conducted by Sandia laboratories to validate these models for large LNG spills on water. It was observed that the pool fire did not extend across the entire area of an $80 \mathrm{~m}$ diameter LNG pool. In addition, the flame height was greater than expected and there was very little smoke obscuration compared to the $35 \mathrm{~m}$ tests at Montoir. This combination of physical phenomena made it difficult to use existing models to predict the consequences of thermal radiation, especially when extrapolating to different and potentially larger spill sizes.

A recent study using empirical analysis and CFD demonstrated that the thermal updraft of a large fire will drive an inward flow of air and natural gas from the non-burning region with a velocity greater than the burning velocity of the outwardly spreading pool fire. Medium scale tests using a $4 \times 1 \mathrm{~m} \mathrm{LNG}$ pool in a fire tunnel confirmed that an artificially generated air-flow of $2.8 \mathrm{~m} / \mathrm{s}$ was sufficient to stop the flame spread across the pool and confirmed the previous analysis.

This paper describes an empirical model that has been developed based upon this analysis to account for the reduced pool fire size and successfully model the larger flame height that was observed during the Phoenix test. An analysis of large spills using this model showed that the calculated flame view factor was significantly reduced compared to pool fire models that predict that the fire will extend across the whole spill surface. The paper will also discuss the effect of water on combustion and hence provide an explanation for the reduced smoke obscuration that was seen during the Phoenix tests.
\end{abstract}




\section{Introduction}

World production of liquefied natural gas (LNG) continues to increase annually and has risen from $160 \mathrm{mmtpa}$ in 2007 to $258 \mathrm{mmtpa}$ in 2016 [1]. There have been corresponding increases in the number of facilities involved in the production and transportation of liquefied gas, including marine LNG carriers (LNGC), LNG import and export facilities and Floating LNG (FLNG) facilities that are currently being commissioned. It is therefore important to be able to assess the consequences from a potential catastrophic failure of LNG storage to manage the hazards appropriately. The accidental loss of containment of LNG could result in a large evaporating/boiling pool, which, if ignited, could generate damaging levels of thermal radiation at large distances. The thermal radiation could affect vessels and their crews, the port facilities and corresponding on site population, as well as affecting the public perception regarding the safety of LNG.

There have been relatively few large-scale pool fire tests carried out on LNG, especially on water [2]. Therefore, to improve the quantification of the pool fire hazard the Department of Energy (DOE) funded a programme of research at Sandia National Laboratories. As part of this work, two LNG spill and pool fire tests were carried out at the Sandia large scale test complex in Albuquerque in 2009 by Blanchat et al. [3]. The first test produced a typical LNG pool fire with a diameter of $20 \mathrm{~m}$. However, in the second test with an average spill diameter of approximately $80 \mathrm{~m}$, the fire did not extend to the upwind edge of the LNG pool and covered only about $50 \%$ of the total area of the spill. An image of the second test is shown in Figure 1. In addition, there was relatively little smoke production during this test, especially compared to the previous large test at Montoir [4] and the flame height to fire diameter ratio was significantly higher than would have been expected from established correlations [5].

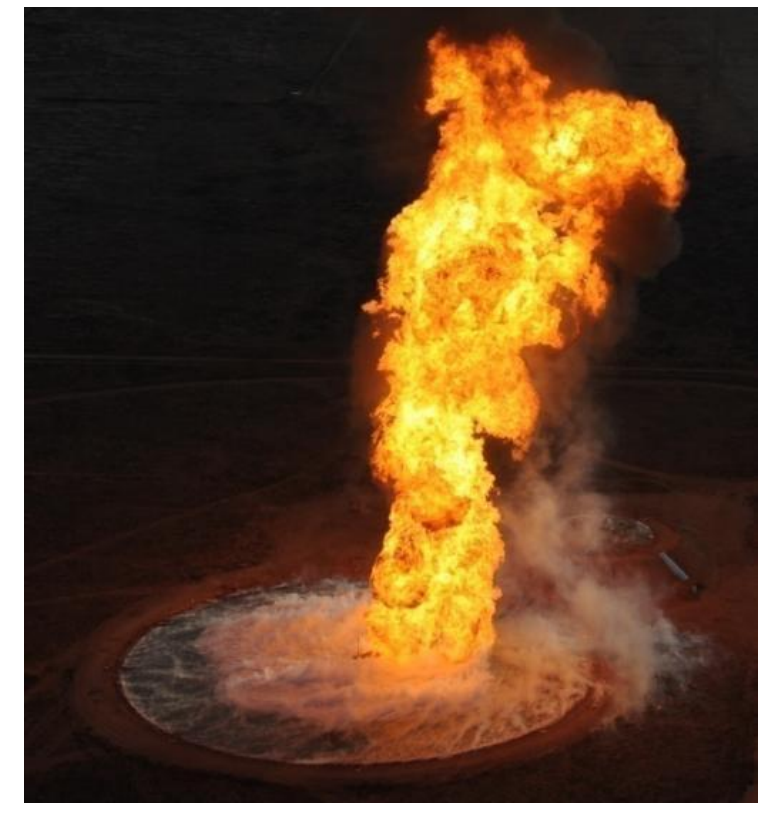

Figure 1: An aerial image of Phoenix Test 2 at 250 s (Source: Blanchat et al. [3]) 
The outcome of the second Phoenix test, especially the lack of smoke, was certainly unexpected within the industry [6]. Therefore, to ensure that any safety assessment did not under predict, it was recommended that LNG pool fires should be modelled with a much higher Surface Emissive Power (SEP) than previous models to account for the lack of smoke shielding compared to previous tests [4]. In addition, the recommendation by Luketa was to model the LNG fire above the whole spill area [7], because it was difficult to predict the extent of the non-burning region without a physical basis. In a later analysis, Luketa and Blanchat suggested that the non-burning region was partly due to a low Damköhler number, where fire extinguishment occurs because diffusion rates are similar or higher than chemical reaction rates necessary to sustain the fire at the pool fire edge [8]. They concluded that the higher diffusion rate could be attributed to the higher entrainment velocities of the large pool fire in the second Phoenix test, but there was a lack of data to quantify the effect and so predict the size of the non-burning region.

A similar theory was proposed by Betteridge el al. to explain both the non-burning region and the high flame height seen in the second Phoenix test [9]. They postulated that on water, high rates of vaporization of LNG are sustained in these outer areas and the inward flow (driven by thermal convection in the central fire) is so strong that the flame cannot spread outwards across the whole pool spill. LNG vaporization in the non-burning area means that in the lower part of the pool fire, the flames entrained a mixture of air and LNG rather than just air, which produces an increase in the total burning rate and hence flame height. The flame height to diameter ratio is greater than in fully burning pool fires because vaporization occurs over a larger area than just the extent of the burning area. This was verified experimentally in a series of medium scale tests to quantify the flame burning speed and determine if it could be halted by an artificial air flow flowing in the opposite direction [10]. The results of this analysis are used in this paper to develop a model to predict the observations seen during the Phoenix tests and hence to allow the quantification of thermal effects from LNG pool fires for a range of spill sizes.

\section{Flame speeds above LNG pools}

In previous work Betteridge et al. estimated the entrainment velocity of the inward flow across the surface of the non-burning areas of the LNG pool in the second Phoenix test to be 2 to $3 \mathrm{~m} / \mathrm{s}$. This was achieved by tracking the position of visible turbulent eddies [9] from a frame-by-frame analysis of a short section of one of the videos. Although this was a simple calculation, the analysis was supported by computational fluid dynamic (CFD) modelling using the ANSYS CFX code [11]. In this CFD model the fire was represented as a distributed heat source within a prescribed volume and the model determined the thermal buoyancy driven inflow across the non-burning region. Typical results for a $50 \mathrm{~m}$ diameter fire above a $80 \mathrm{~m}$ diameter LNG spill are shown in Figure 2, which shows the wind velocity and concentration from the pool center to the radius of the spill. 


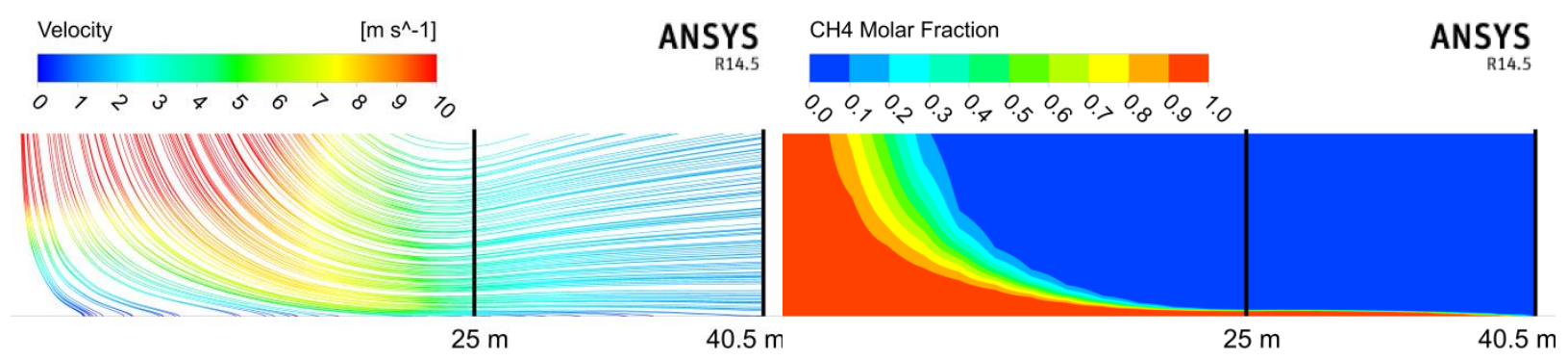

Figure 2: Contour plots of wind velocity streamlines (left) and methane concentration (right) above the surface of the LNG pool calculated in ANSYS. The center of the pool is on the left-hand side in each case.

The CFD results supported the empirical analysis and showed that the entrainment velocity of the inward flow of air increased from $1 \mathrm{~m} / \mathrm{s}$ to over $3 \mathrm{~m} / \mathrm{s}$ at the edge of the fire. In addition to entraining air, the fire also entrained methane released from the non-burning regions of the LNG pool. This can be envisaged more clearly by plotting the results at specific distances from the edge of the fire, as can be seen in Figure 3. The CFD results predicted that the flammable range (0.05 $\mathrm{v} / \mathrm{v}$ to $0.14 \mathrm{v} / \mathrm{v}[12])$ was present over a very narrow range of heights and near the fire this range was centered on $y=0.35 \mathrm{~m}$. At this height, the corresponding inward flow velocity is slightly lower than the maximum value and is predicted to be approximately $3.6 \mathrm{~m} / \mathrm{s}$ at the edge of the fire.
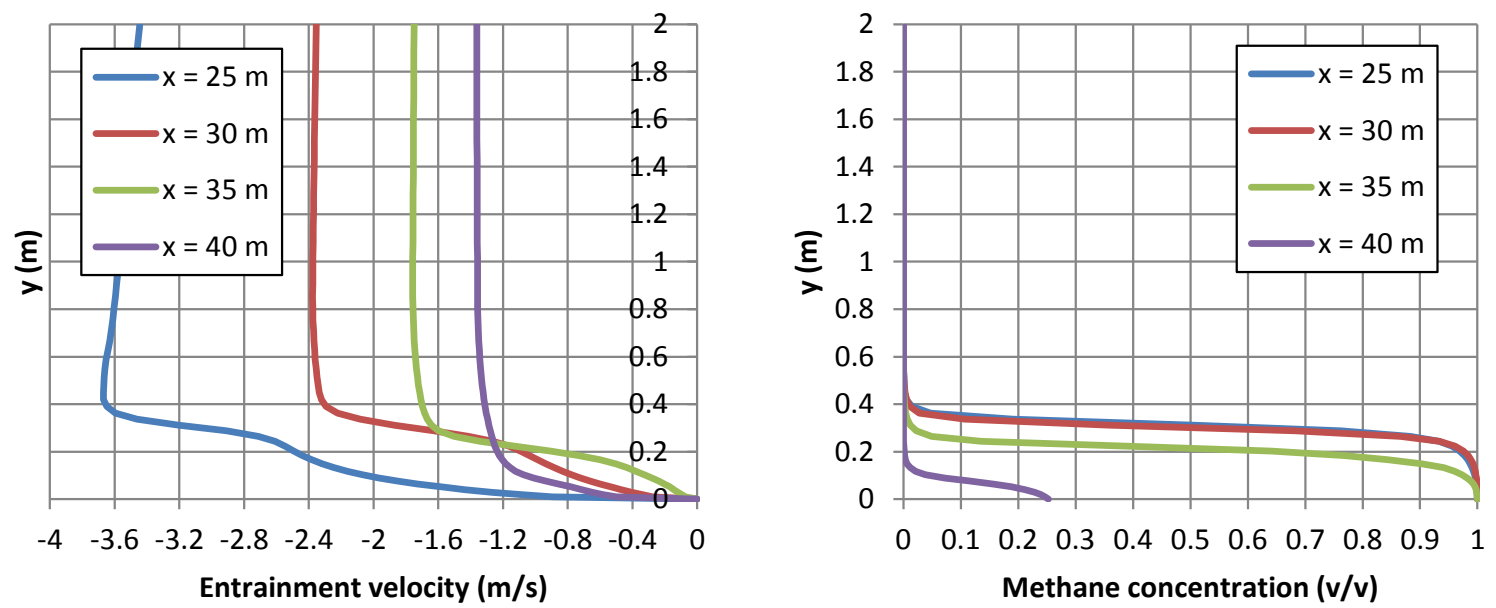

Figure 3: Profiles of entrainment velocity and methane concentration at $x=25,30,35$ and $40 \mathrm{~m}$ from the pool center.

By comparison, the theoretical rate of flame spread is expected to be lower than these calculated values and this supports the basis for a physical mechanism for the non-burning region. For instance, experiments using alcohols and jet fuels at temperatures $50^{\circ} \mathrm{C}$ above their flashpoint showed the maximum rate of flame spread was approximately $2 \mathrm{~m} / \mathrm{s}$ [13].

This rate of flame spread is significantly greater than the laminar burning velocity, which for methane is approximately $0.45 \mathrm{~m} / \mathrm{s}$ [12]. The rate of flame spread is enhanced for two reasons. The first is that the laminar burning velocity is the rate at which the flame propagates into unburned gas in the frame in which the unburnt gas is stationary. However, this does not consider the expansion associated with combustion. In fact, the unburnt gas moves at a speed of $(\sigma-1) S_{\mathrm{u}}$, where 
$S_{\mathrm{u}}$ is the burning velocity and $\sigma$ is the expansion ratio. For flames in the open, such as pool fires, the flame speed is expected to be $\sqrt{\sigma} S_{u}$ [14] and therefore for methane this is approximately $2.5 \times \mathrm{S}_{\mathrm{u}}$. A second factor can be attributed to the curvature of the flame front (as viewed in the vertical plane), which increases the perimeter over which the flame can propagate into the unburned gas [14]. The enhancement factor is approximately 1.5 for laminar flames and can be higher if the flames are turbulent. However, the turbulence needs to be on a length scale similar to the depth of the flammable layer, which is predicted to be relatively narrow from the CFD analysis.

The flame propagation rate is not the only factor to determine the extent of the non-burning region, otherwise these regions would be a common occurrence above all pool fires. Consequently, the height of the flammable region is also likely to be a significant factor. The CFD analysis showed the flammable region lies $0.35 \mathrm{~m}$ above the LNG pool surface, which is significantly higher than the flammable region above less volatile hydrocarbons pools. Consequently, the inward flow velocity in the flammable region is closer to the overlying airflow predicted by CFD and observed during the second Phoenix test. This was demonstrated by Paxton and Dismile, who measured the resultant flame speed of methanol when an opposing air flow was applied [15]. The flame velocity was measured to be $1.08 \mathrm{~m} / \mathrm{s}$ even when there was an opposing air flow of $2.6 \mathrm{~m} / \mathrm{s}$. In this experiment the fuel temperature was only $10^{\circ} \mathrm{C}$ above the flashpoint of methanol and so the flammable region was predicted to be very close to the fuel surface, where the effect of the air flow was less significant.

In another study of the Phoenix tests, Kelsey et al. [16] used the Fire Dynamics Simulator (FDS) CFD code to investigate the sensitivity of the air flow behavior to assumptions about the burning rate, the radiative fraction, grid resolution and choice of turbulence model. For a burn rate of 0.1 $\mathrm{kg} / \mathrm{s} \mathrm{m}^{2}$, the inward entrainment velocities were predicted to range from $1.8 \mathrm{~m} / \mathrm{s}$ to $3.2 \mathrm{~m} / \mathrm{s}$ for fire diameters from 20 to $50 \mathrm{~m}$. In addition, the predicted entrainment velocity was found to be relatively insensitive to mass burning rate, over the large range of burning rates tested $(0.1$ to $0.45 \mathrm{~kg} / \mathrm{s} \mathrm{m}^{2}$ ).

\section{Mid-scale testing of flame speeds}

The empirical evidence and CFD modelling provided good evidence for the physical origin of the non-burning region, but it is difficult to have confidence in the CFD models to extrapolate for different pool sizes. Therefore, Shell commissioned a research programme to experimentally determine the propagation speed of flames across LNG pools [10]. A schematic of the experimental setup is shown in Figure 4, in which the LNG was constrained to a $4 \times 1 \mathrm{~m}$ shallow pool. A bank of fans at the upwind end of the pool provided a uniform air flow down the tunnel and, once these fans were started, the flammable vapor at the downwind end of the pool was ignited. The under surface of the metal tray could be sprayed with hot water to simulate boil off rates on water and so the rate could be controlled between 0.075 and $0.11 \mathrm{~kg} / \mathrm{s} \mathrm{m}^{2}$. 


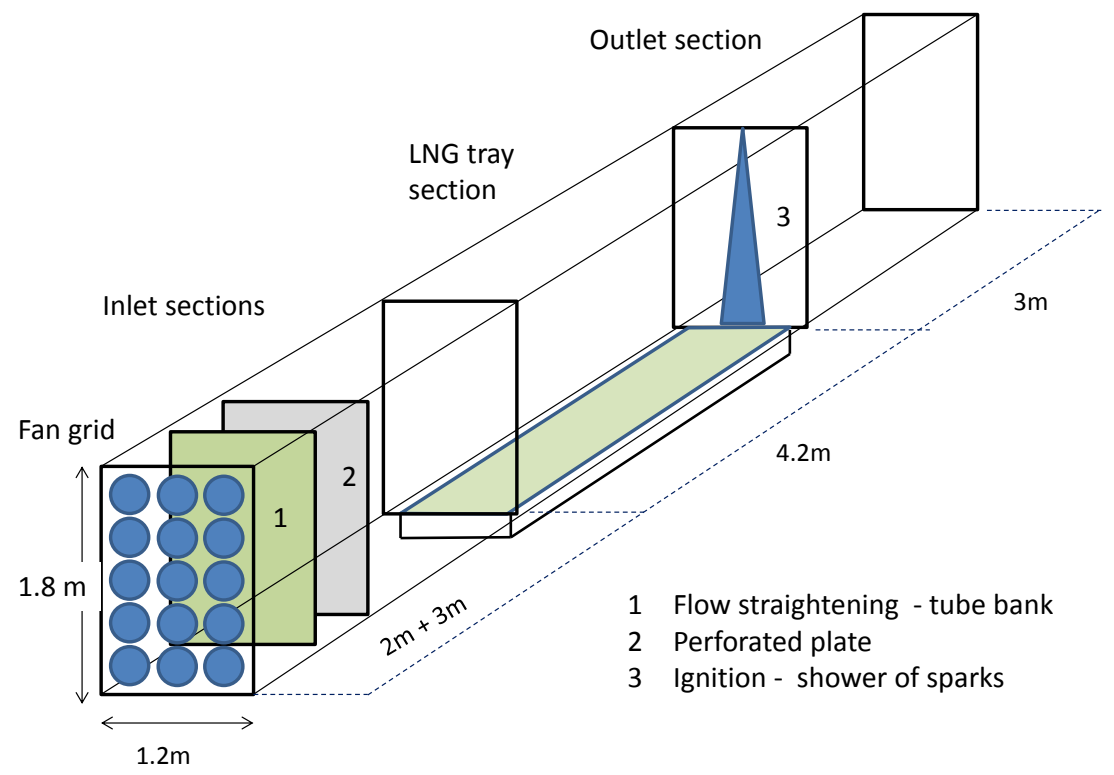

Figure 4: Schematic layout of experiment to determine the rate of flame spread above a LNG pool

In total six experiments were completed with a range of boil off rates and air velocities. It was found that at an air flow of $2.4 \mathrm{~m} / \mathrm{s}$ the flame spread to the upwind edge of the pool. When the air flow was raised to $2.8 \mathrm{~m} / \mathrm{s}$ and $3.2 \mathrm{~m} / \mathrm{s}$ the progress of the flame in an upstream direction was arrested part way down the tunnel. The spread of flame was most rapid in the low speed flow region, close to the walls, but the imposed airflow was sufficient to prevent sustained flame spread even in these regions. Consequently, the resultant quasi-steady flame fronts on both sides of the tunnel formed a characteristic V-shape when viewed from above, as can be seen in Figure 5. The component of the air speed perpendicular to the flame front was calculated from the angle of the well mixed region burning with a blue flame and used as a basis for estimating the turbulent flame speed relative to gas with zero average velocity. 


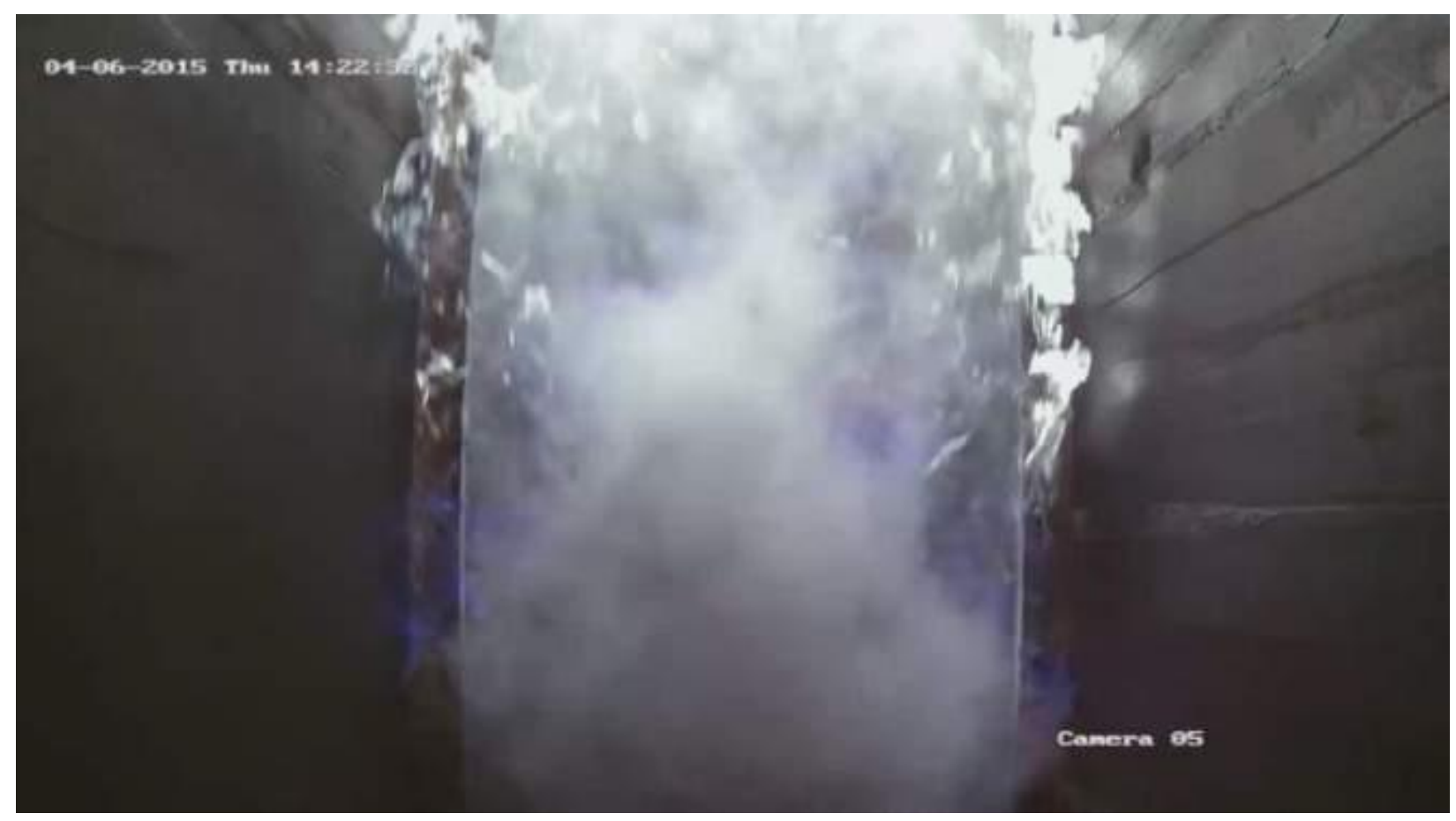

Figure 5: The angled flame front from the LNG fire viewed from above for an air speed of $2.8 \mathrm{~m} / \mathrm{s}$.

The measured angle fluctuated between $20^{\circ}$ and $40^{\circ}$ during each of the tests with air flows of 2.8 $\mathrm{m} / \mathrm{s}$ and $3.2 \mathrm{~m} / \mathrm{s}$ and did not appear to be influenced by the boil off rate within the uncertainty of the measurement. Consequently, the maximum turbulent flame speed was calculated to lie between 1.0 and $2.0 \mathrm{~m} / \mathrm{s}$ and so consistent with the values discussed earlier in the literature [13], [14].

\section{CFD analysis of mid-scale tests}

CFD modelling using ANSYS was also used to help interpret the mid-scale experimental results. The geometry was modelled using the Eddy Dissipation combustion model coupled with a simple sub-model for non-burning behavior called the products limiter model. This model was selected due to its widespread use for modelling combustion and its relatively simplicity. Several simulations were carried out; the first set involved prescribing the location of non-burning regions, whilst second set sought to investigate the predictive capability of the model to calculate nonburning regions.

Early work suggested that the products limiter could be used to obtain behavior that matched the experiments, as can be seen in Figure 6, where the flame front clearly shows a ' $v$ ' shape with an angle like those seen during the experiments. In this case the ' $v$ ' shape has been predicted based on the concentration of products. This is because products close to the tunnel walls are less susceptible to being blown down wind and therefore the model predicts more combustion in these regions. 


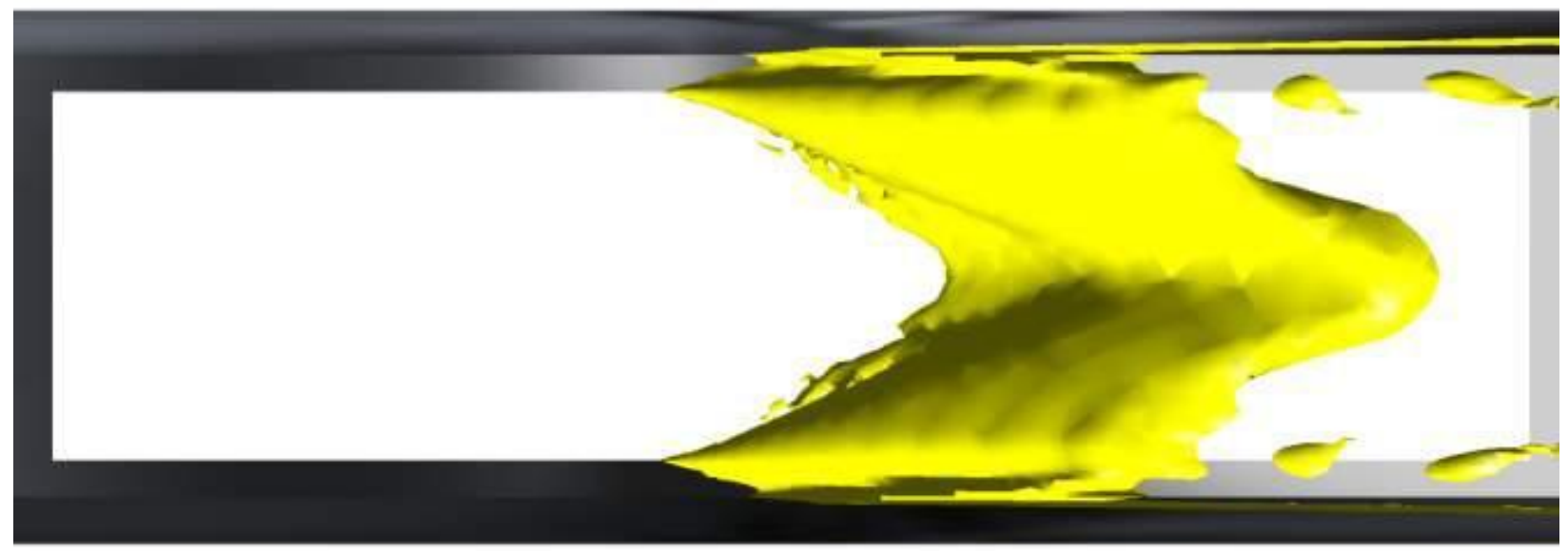

Figure 6: An overhead view of the reaction rate iso-surface for $3 \mathrm{~mol} / \mathrm{m}^{3} / \mathrm{s}$ calculated using the product limiter sub-model in ANSYS, when an air flow of $3.2 \mathrm{~m} / \mathrm{s}$ has been applied from the left.

However, the model also predicted an unphysically thick flame front due to flames propagating through gas mixtures where the concentration was above the upper flammable limit. This appears to be a weakness within the Eddy Dissipation combustion methodology itself. So, although the CFD model could model the behavior observed in the experiments, tuning would need to be applied on a case-by-case basis. Consequently, the CFD model could not be used to predict the location of non-burning regions in large-scale LNG pool fires and certainly not without further fundamental development.

\section{Calculating size of non-burning regions}

In the previous sections, it was deduced that the maximum speed that LNG fires could traverse across a LNG spill pool was approximately $2 \mathrm{~m} / \mathrm{s}$. This was lower than the entrainment inflow velocity created by the thermal buoyancy of the fire during the second Phoenix test, which was measured to be $2-3 \mathrm{~m} / \mathrm{s}$ and predicted to be as high as $3.7 \mathrm{~m} / \mathrm{s}$ from a CFD analysis of the geometry of the second Phoenix test. To extend this observation further, and develop a generic model, it is important to quantify the entrainment velocity and hence determine the maximum fire size before the non-burning region starts to develop.

Several correlations exist for entrainment into fire plumes, including Thomas et al. [5], Zukoski et al. [17] and Heskestad [18]. Historically in these correlations there has also been little consensus regarding the relationship between the entrainment rate and the height above the fire source, $y$. Some correlations vary linearly with y (Heskestad, [18]), whilst others vary with $\mathrm{y}^{3 / 2}$ (Thomas, [5]) or even $y^{5 / 2}$ (Zukoski et al., [17). More recently, Zukoski [19] and Heskestad [20] agree that entrainment rate measurements tend to scale linearly with y. Following the approach taken by Heskestad [18], we can calculate the entrainment velocity from Equation 1.

$$
U_{e}=\frac{\dot{m}_{e}}{\rho_{a} \pi D_{f}}
$$


Where $\dot{m}_{e}$ is the entrainment mass flow rate per meter of height into the fire with units of $\mathrm{kg} / \mathrm{s} \mathrm{m}$, $\rho_{\mathrm{a}}$ is the ambient air density and the $\mathrm{D}_{\mathrm{f}}$ is the fire diameter. The parameter $\dot{m}_{e}$ can be calculated from Equation 2, where $\dot{m}_{f}$ is the mass flow rate in the fire.

$$
\dot{m}_{e}=\frac{d \dot{m}_{f}}{d y}
$$

Equation 2

If the mass flow rate in the fire is linearly dependent on y and defining $\dot{m}_{f}=0$ at y $=0$ and $\dot{m}_{f}=$ $\dot{m}_{f, H}$ at $\mathrm{y}=\mathrm{H}$ (the fire height), it follows that the entrainment flow rate can be related to the convective heat release rate, $\mathrm{Q}_{\mathrm{c}}$ in $\mathrm{kW}$, and fire height.

$$
\dot{m}_{e}=\frac{0.0054 Q_{c}}{H}
$$

Equation 3

Following the Heskestad correlations for flame height and assuming a convective heat release rate of $70 \%$, the entrainment velocity can be calculated with respect to fire diameter and depends on both the regression rate and ambient air density.

The entrainment velocities calculated from this correlation are plotted as a function of pool fire diameter in Figure 7 for two regression rates; $0.147 \mathrm{~kg} / \mathrm{s} \mathrm{m}^{2}$, as calculated by Luketa and Blanchat [8] and $0.18 \mathrm{~kg} / \mathrm{s} \mathrm{m}^{2}$ corresponding to the lower value obtained in the China Lake tests [2]. For each regression rate, two lines are plotted to show the influence of ambient air density on the calculated value. The values chosen, $1.1 \mathrm{~kg} / \mathrm{m}^{3}$ and $1.3 \mathrm{~kg} / \mathrm{m}^{3}$, are for an ambient pressure of 845 mbar and correspond to a temperature of $-2^{\circ} \mathrm{C}$ (air temperature during the second Phoenix test) and $-45^{\circ} \mathrm{C}$ (an arbitrary lower value to represent cooling of air by natural gas from the pool) respectively. As can be seen from Equation 1, increasing the density reduces the calculated entrainment velocity.

The values for entrainment velocity calculated from CFD analysis; ANSYS [9] and FDS [16] are also plotted when the fire is burning above the whole spill area, e.g. there is no non-burning region, and for a regression rate of $0.147 \mathrm{~kg} / \mathrm{s} \mathrm{m}^{2}$. The results of the CFD analysis and the Heskestad correlations show that the entrainment velocity is predicted to exceed $2 \mathrm{~m} / \mathrm{s}$ when the fire diameter is approximately 20-30 m and hence it can be postulated that the non-burning region starts to form when the LNG spill diameter exceeds this value. 


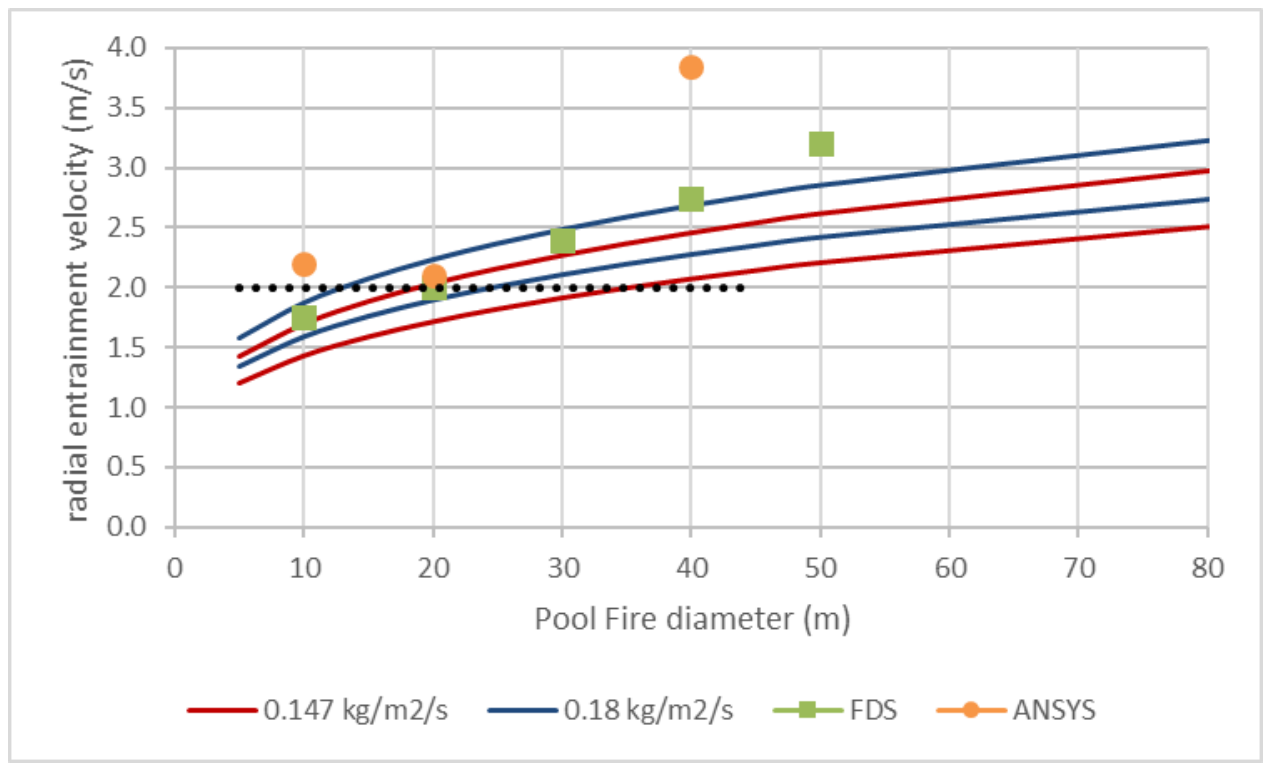

Figure 7: Calculated entrainment velocities for a range of fire diameters. The two lines for each regression rate correspond to $\rho_{\mathrm{a}}=1.1$ and $1.3 \mathrm{~kg} / \mathrm{m}^{3}$ in the Heskestad correlations [18]

Evidence from the Phoenix tests indicates that a non-burning region was present during Test 1, which had a $21 \mathrm{~m}$ pool fire diameter [8], but clearly the fire diameter was significantly larger than 20-30 m during Test 2. This is most likely due to the flame anchoring to the discharge pipe berm, where it extended a short distance upwind of the spill center and extensively downwind, as can be seen in Figure 8. Around the berm, the entrained velocity will be reduced and so would have allowed the flame to spread locally, like the edge effects seen in the mid-scale tests (see Figure 5). In addition, the potential for flame spread in the presence of obstacles could be increased by congestion elements in the non-burning areas with a length scale comparable to the depth of the flammable layer. An extrapolation of an analysis of the flame turbulence during the mid-scale tests showed that obstacles a few hundred millimeters in diameter, and within a few meters of the water surface, would be sufficient to increase the burning speed of the flame [10].

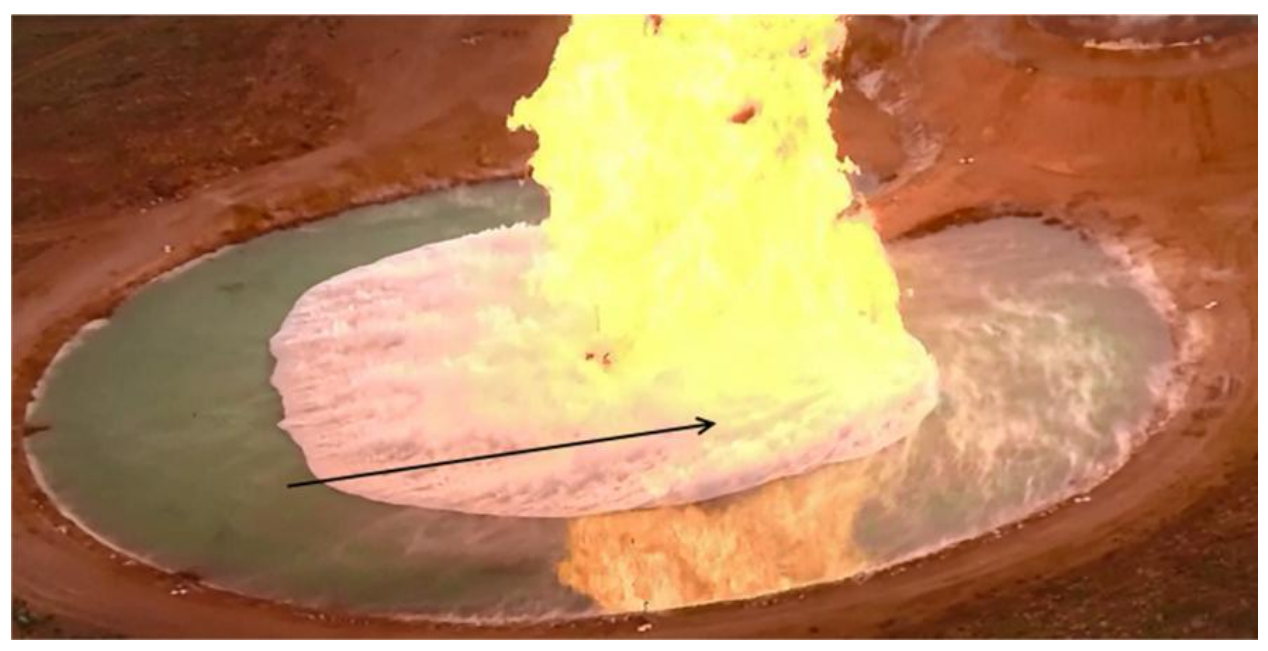

Figure 8: Image showing the non-burning region during the second Phoenix test - the arrow indicates the wind direction. (Source: Blanchat et al. [3]) 
In the context of a spill on open water, such obstacles are unlikely to be found in practice. But what could be the reason that flames spread across the whole pool area during the $35 \mathrm{~m}$ Montoir tests? In this case the flame could have stabilized on the rim of the bunded pool and spread across the whole pool due to both a lower entrainment velocity and increased flame burning speeds adjacent to the rim.

In conclusion, when a LNG pool spill grows larger than $30 \mathrm{~m}$, non-burning regions would start to develop over open water. This is slightly larger than the diameter reported previously [10] to account for the uncertainty shown in this analysis and to ensure the model was developed to be slightly conservative. Within the model this resulted in a maximum pool fire diameter of $30 \mathrm{~m}$, irrespective of the overall spill diameter.

\section{Regression rate}

The regression rate is a key parameter in the calculation of the flame height, because it is used to determine the quantity of fuel that is burnt. However, it is a difficult parameter to measure directly and usually it is inferred from the pool fire lifetime and so values of between $0.1 \mathrm{~kg} / \mathrm{s} \mathrm{m}^{2}$ to 0.25 $\mathrm{kg} / \mathrm{s} \mathrm{m}^{2}$ have been reported for large scale experiments involving LNG pool fires [6]. This difficulty continued during the Phoenix test series and Luketa and Blanchat reported that it was not possible to measure a regression rate for the second test because the LNG release was transitory and lasted less than five minutes [8]. Whereas a steady state period was obtained for the first test and a regression rate of $0.147 \pm 0.01 \mathrm{~kg} / \mathrm{s} \mathrm{m}^{2}$ [8]. Surprisingly, this value is only slightly higher than the value reported from the Montoir tests, $0.141 \mathrm{~kg} / \mathrm{s} \mathrm{m}^{2}$ [4], since the water substrate would be expected to act as a heat reservoir and so increase the regression rate to be closer to the China Lake tests $0.17-0.25 \mathrm{~kg} / \mathrm{s} \mathrm{m}^{2}$ [2].

The Shell major hazard consequence tool, FRED, which uses the Thomas correlation [5] for flame height, was adapted to use a regression rate of $0.147 \mathrm{~kg} / \mathrm{s} \mathrm{m}^{2}$. FRED predicted a value of $34 \mathrm{~m}$, which is in good agreement to the height of $34 \mathrm{~m}$ measured during the first Phoenix test. However, FRED significantly under predicted the flame height that was observed during the second Phoenix test; $146 \mathrm{~m}$ measured versus a calculated value of $100 \mathrm{~m}$. The regression rate would need to be increased to approximately $0.27 \mathrm{~kg} / \mathrm{s} \mathrm{m}^{2}$ to get good agreement with the flame height using the Thomas correlation. A justification for increasing the regression rate was provided by Betteridge et al., who showed that the regression rate should be adjusted by the ratio of pool spill to pool fire areas to account for the methane fuel that is entrained into the fire from the non-burning area [9]. For the dimensions of the second Phoenix test, this would give an adjusted regression rate of approximately $2.25 \times 0.147=0.33 \mathrm{~kg} / \mathrm{s} \mathrm{m}^{2}$.

However, a regression rate of $0.147 \mathrm{~kg} / \mathrm{s} \mathrm{m}^{2}$ could not be applied to the non-burning region and although thermal radiation from the fire could have a limited affect in the region immediately adjacent to the fire, the condensation cloud is expected to insulate the majority of the non-burning region. Therefore, the non-burning region was modelled using the regression rate for LNG on water, where it is assumed that the water acts as an infinite heat reservoir. This is a reasonable assumption on open water, such as a harbor, but may overpredict static areas of water, such as in the Phoenix experiments, where ice and hydrates formed.

The transient pool model in FRED, which is similar to the Exxon LSM90 model incorporated into HGSYSTEM [21], was used to calculate the steady state regression rate for LNG on water. The 
calculated value for a range of pool sizes was approximately $0.086 \mathrm{~kg} / \mathrm{s} \mathrm{m}^{2}$ and was used for the regression rate in the non-burning regions of the spill. The difference between this value and a steady state value of $0.05 \mathrm{~kg} / \mathrm{s} \mathrm{m}^{2}$ for LNG on concrete was also used to determine an adjusted value for the pool fire burning rate on water by combining the value obtained from the Montoir experiments to account for the additional boil off rate due to the heat reservoir of the water substrate. This gives an adjusted pool fire regression rate of $0.177 \mathrm{~kg} / \mathrm{s} \mathrm{m} \mathrm{m}^{2}$, and hence was comparable to the lower end of values measured during the China Lake tests [2].

These regression values and the maximum pool fire diameter of $30 \mathrm{~m}$ were used in the following equations to determine an equivalent regression rate, $\boldsymbol{m}$, that could be used within the Thomas correlation to determine the flame height.

$$
\begin{gathered}
D_{f}=D_{p} \text { if } D_{p} \leq 30 \\
D_{f}=30 \text { if } D_{p}>30 \\
\dot{m}_{p}^{\prime}=0.086 \times \frac{\pi}{4}\left(D_{p}^{2}-D_{f}^{2}\right) \\
\dot{m}_{f}^{\prime}=\frac{\pi D_{f}^{2}}{4} \times 0.177 \times\left(1-e^{\left(-1 \times k D_{f}\right)}\right)
\end{gathered}
$$

Equation 4

Equation 5

Equation 6

Where $\mathrm{k}$ is the burning rate coefficient $=0.136$ per meter to account for reduced thermal radiation to the LNG pool when the fire is not optically thick [22].

$$
\dot{m}=\frac{\left(\dot{m}_{f}^{\prime}+\dot{m}_{p}^{\prime}\right)}{\pi / 4 \times D_{f}^{2}}
$$

Equation 7

The limit of $30 \mathrm{~m}$ in Equation 4 is for modelling LNG pool fires on open water. It should be adjusted if objects are present in the water, such as the discharge berm in the Phoenix tests, or the LNG is spilled against the side of a LNG carrier. By using the fire and pool diameters observed in the Phoenix tests [8], the adjusted regression rate calculated using Equation 7 was $0.168 \mathrm{~kg} / \mathrm{s} \mathrm{m}^{2}$ for Test 1 and $0.28 \mathrm{~kg} / \mathrm{s} \mathrm{m}^{2}$ for Test 2 . This is in good agreement with value calculated previously using the simple approach of the ratio of pool spill to pool fire areas.

The experimental and calculated flame heights using the new model are given in Table $1^{1}$. The results show that the updated model provides good agreement with the flame heights observed during both Phoenix experiments.

\footnotetext{
${ }^{1}$ An average air density of $1.08 \mathrm{~kg} / \mathrm{m}^{3}$ was used for both tests
} 
Table 1: A prediction of flame heights for the Phoenix LNG pool fire experiments (Pool fire diameter measured at height of $15 \mathrm{~m}$ )

\begin{tabular}{|c|c|c|c|c|}
\hline \multirow{2}{*}{$\begin{array}{c}\text { Phoenix } \\
\text { test }\end{array}$} & \multicolumn{2}{|c|}{ Experiment } & \multicolumn{2}{c|}{ Predicted flame height $(\mathrm{m})$} \\
\cline { 2 - 5 } & $\begin{array}{c}\text { Pool fire } \\
\text { diameter }(\mathrm{m})\end{array}$ & $\begin{array}{c}\text { Measured flame } \\
\text { height }(\mathrm{m})\end{array}$ & $\begin{array}{c}\text { Current FRED } \\
\text { model }\end{array}$ & $\begin{array}{c}\text { Updated } \\
\text { model }\end{array}$ \\
\hline 1 & 21.7 & 34 & 32 & 36 \\
\hline 2 & 56.1 & 146 & 100 & 151 \\
\hline
\end{tabular}

\section{Soot production}

One of the main observations during the Phoenix tests was the lack of significant smoke and hence a significant higher average Surface Emissive Power (SEP) than seen during the $35 \mathrm{~m}$ diameter tests at Montoir [4]. Luketa and Blanchat discussed two possible physical effects that may have caused the limited soot production and hence smoke [8]; a reduced atmospheric pressure due to the elevation of the Sandia site and the addition of water vapor from the water substrate. In their paper, they showed that pressure scaling modelling could not explain the difference to the Montoir tests, but there was good anecdotal evidence that water vapor from the substrate could be the explanation.

They highlighted several studies from laboratory scale tests that show smoke production was less if the water concentration, either in pre-mixed or non-pre-mixed air fuel mixtures, was increased. But, there is very little work on the measurement of soot production rates in large fires and singularly absent for LNG fires. It is expected that water vapor affects soot formation through four mechanisms summarized below [23]:

- The dilution of oxygen as water vapor is added to dry air. This will reduce the adiabatic flame temperature and so lead to lower rates for soot nucleation and surface growth. However, this approach is also likely to weaken soot oxidation by oxygen, and hence tend to increase the soot concentrations, although it is not expected to be significant.

- A reduction of flame temperature caused by the higher heat capacity of water vapor.

- Altering the chemical reactions through the generation of the hydroxyl radical and hence alter the concentrations of important species for soot formation, such as $\mathrm{H}, \mathrm{H} 2, \mathrm{C} 2 \mathrm{H} 2$, and A4 (pyrene).

- Added water vapor participates in radiative exchange and so can modify the flame temperature and thus alter soot production and oxidation.

The effect of water vapor on chemical reactions was investigated using the chemical kinetics solver Cosilab [24]. In this analysis, a well-established reaction mechanism for methane-air combustion, GRI Mech [25], was used within the solver to model the combustion and acetylene was used as the precursor for soot nucleation and growth [26]. An important characteristic of this model is that acetylene is not the actual fuel but assumed to be the product of the fuel breakdown process. Hence, the rates of soot nucleation and growth are directly proportional to the acetylene concentration rather than to the parent fuel concentration.

The calculated acetylene mass fraction as a function of fuel-air mixture fraction for different water fractions are shown in Figure 9. They graphs indicate that the soot concentration decreased when water vapor was added to either the fuel or oxidizer. Subsequently, the acetylene mass fraction 
was correlated directly to soot mass fraction and, indirectly, via pyrene, A4 (which consists of 4 benzene rings). In both cases, the soot mass fraction obtained was then related to an equivalent smoke visibility. Even though this approach gave good qualitative results and showed a decline in soot concentration with enhanced water vapor concentration, realistic values of visibility through the fire were not obtained and so it was not possible to use this approach to extrapolate to different scenarios and fire sizes.

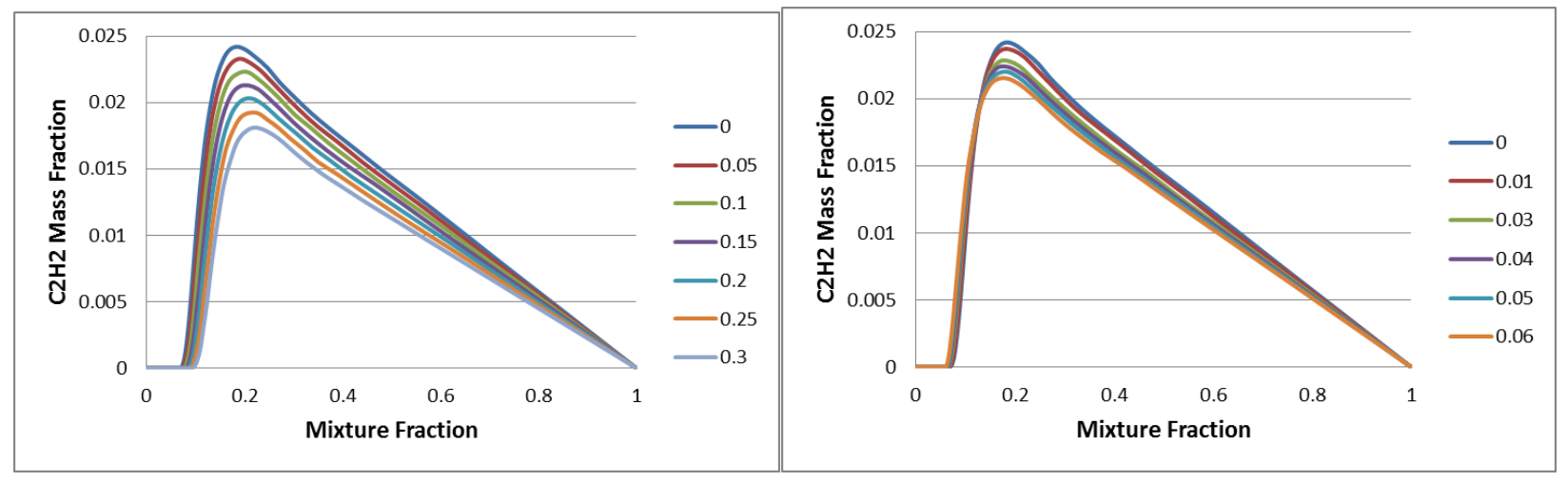

Figure 9: The mass fraction of acetylene $\left(\mathrm{C}_{2} \mathrm{H}_{2}\right)$, and hence soot generation, as a function of air fuel mixture fraction when different mass fractions of water are added to the fuel stream (left graph) and air stream (right graph).

Work is still on-going to extend an alternative soot model, where soot inception is assumed to be the result of collision of two pyrene molecules (A4) and hence more realistic than using a soot precursors such as acetylene. Initial results indicate a $45 \%$ reduction in soot concentration when $6 \%$ by mass of water vapor is added to the air.

In the interim it is conservative to assume that smoke shielding does not occur for LNG pool fires on water.

\section{Surface Emissive Power}

It is proposed that the new model should be based upon the solid flame ("integral") pool fire model that is already implemented in FRED [27]. This model assumes a cylindrical tilted body, which has a constant Surface Emissive Power (SEP) across the whole surface. However, as observed during Phoenix tests and discussed in the previous section, smoke shielding at larger diameters did not occur and therefore the SEP within this model needs to be adapted to remove the effect of smoke shielding on the calculated average SEP.

The SEP of a pool fire can be calculated simply by assuming the fuel supplied (calculated from the regression rate) is fully combusted and a fraction of the generated heat is radiated from the surface of the pool fire as shown in Equation 8.

$$
S E P=\frac{f H_{c} \dot{m} \pi^{D_{f}^{2}} / 4}{2 \pi_{f}^{2} / 4+H \pi D_{f}}
$$


Where $\mathrm{f}$ is the fraction of heat radiated (rather than convected out of the fire), $\mathrm{H}_{\mathrm{c}}$ is the heat of combustion, assumed to be $50,000 \mathrm{KJ} / \mathrm{kg}, \dot{m}$ is the regression rate, $\mathrm{H}$ is the flame height and it is assumed that the radiation is emitted from both the top and bottom, as well as the sides of the pool.

The fraction of heat radiated was chosen to be 0.25 . This value was close to that measured in the Phoenix tests; where $0.21 \pm 0.04$ was measured for Test 1 and $0.24 \pm 0.08$ for Test 2 [8]. A comparison of the SEP calculated by the model versus the Phoenix tests is given in Table 2. This shows that the model gives a very good prediction for Test 2, but the prediction for Test 1 is lower than measured. However, when combined with the flame dimensions gave a good prediction of thermal radiation at a distance as shown later.

Table 2: A comparison of predicted SEP versus values measured during Phoenix tests

\begin{tabular}{|c|c|c|c|}
\hline & $\begin{array}{c}\text { Model SEP } \\
\left(\mathrm{kW} / \mathrm{m}^{2}\right)\end{array}$ & $\begin{array}{c}\text { Average narrow } \\
\text { angle SEP [8] } \\
\left(\mathrm{kW} / \mathrm{m}^{2}\right)\end{array}$ & $\begin{array}{c}\text { Average wide } \\
\text { angle SEP [8] } \\
\left(\mathrm{kW} / \mathrm{m}^{2}\right)\end{array}$ \\
\hline Test 1 & 171 & $238 \pm 30$ & $277 \pm 60$ \\
\hline Test 2 & 274 & $282 \pm 101$ & $286 \pm 20$ \\
\hline
\end{tabular}

\section{Application of the LNG pool fire model}

By default, the model assumes that the fire is located at the center of the LNG spill. However, as can clearly be seen in the second Phoenix test, the fire can travel in a downwind direction if the flames are stabilized by solid objects at the water surface or if the wind speed is higher than $2 \mathrm{~m} / \mathrm{s}$ in real scenarios. If this occurs, then the center of the fire should be adjusted and in higher wind speeds the pool fire could travel downwind until its edge aligns with the edge of the LNG spill itself. Consequently, to model Test 2, the center of the pool fire was moved approximately $22 \mathrm{~m}$ towards the South-East edge of the spill area.

The model was validated against the two Phoenix tests using the input data recorded by Luketa and Blanchat [7] and comparing the predicted thermal radiation against data recorded on wide angle radiometers. Graphs showing the measured versus predicted thermal radiation on a 1:1 plot are shown in Figure 10 for Test 1 (left graph) and Test 2 (right graph).

The comparison shows that model gives excellent agreement for the thermal radiation measured in Test 1 , where the majority of data is actually is predicted to be within $\pm 25 \%$ of the measured values. The fractional bias for this analysis is -0.1 , which indicates that the model is slightly conservative. This is slightly surprising considering the predicted SEP is significantly less than the value measured directly in the tests, although this is partly offset by the longer flame length.

The graph for Test 2, shows that the model overpredicts the measured thermal radiation values, with the majority of data points lying within the $50 \%$ boundary. An investigation of the data points that lie outside the $50 \%$ boundary indicated that they were for radiometers that lie closest to the edge of the fire at the East and South instrument towers. This is perhaps not surprising, because the model will assume a uniform flame surface, which is constant over time, whereas detectors close to the flame edge will be susceptible to flame fluctuations. In addition, it was reported that 
intermittent smoke from grass fires may have reduced the measured thermal radiation at the South instrument tower [3].
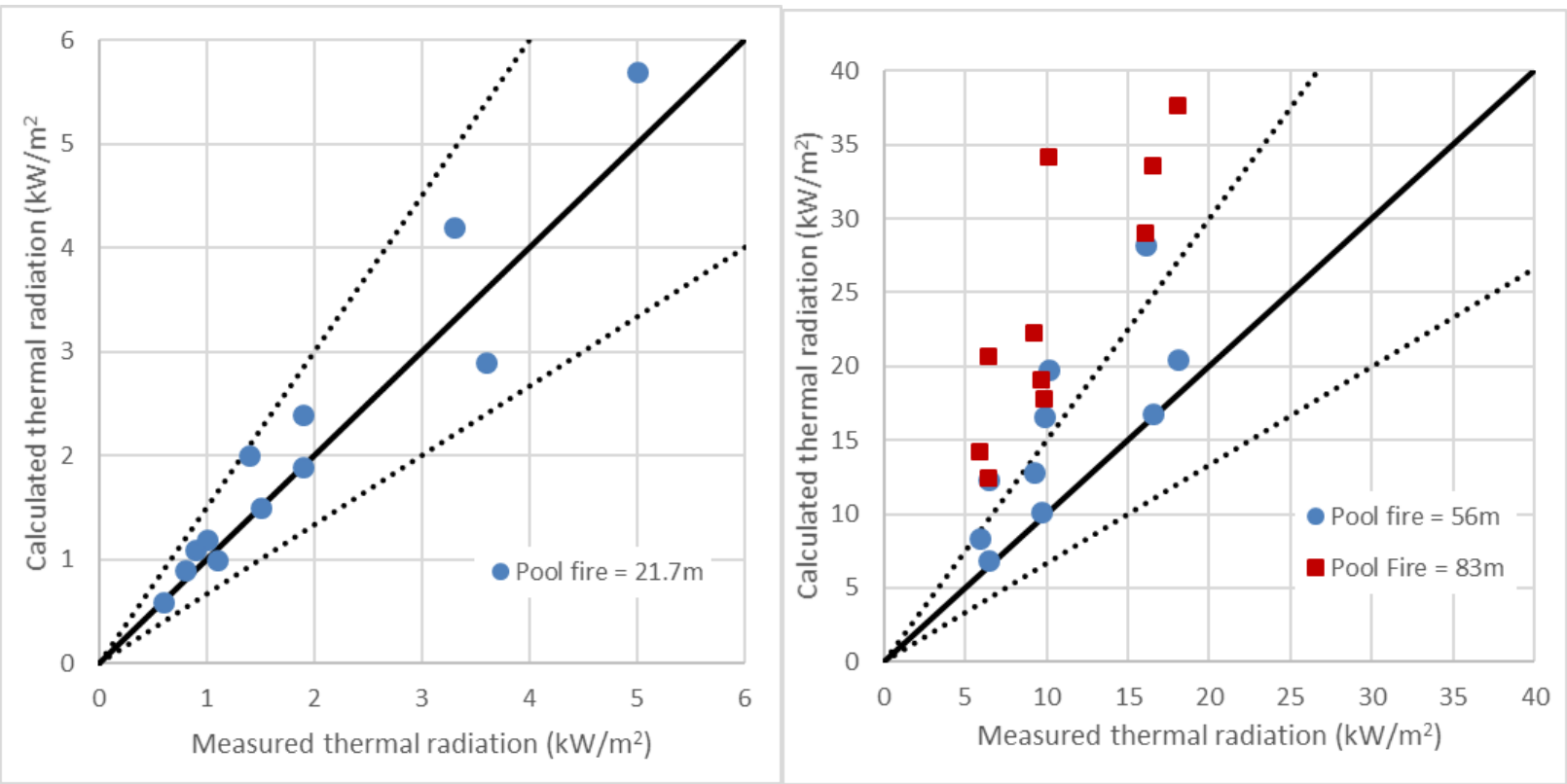

Figure 10: A comparison of predicted values for thermal radiation against measured data for Test 1 (left) and Test 2 (right). The dotted lines indicated $\pm 50 \%$. An equivalent calculation in which the fire area extends to the edge of the $83 \mathrm{~m}$ diameter spill is shown in red for comparison.

Overall it is not clear why the model should overpredict the measured values for Test 2 . The predicted SEP value is slightly less than that observed, whereas the flame length is slightly longer. In addition, the same conservative trend is seen for measurements at each of the instrument towers that are located at the four cardinal directions and so it is unlikely to be the position of the fire relative to the center of the spill. One possibility is that the SEP is not uniform along the full length of the fire and this hypothesis is supported by the narrow angle radiometer data recorded at different heights [3]. From the North spoke, the SEP was measured to be 275 to $306 \mathrm{~kW} / \mathrm{m}^{2}$ between 15 to $55 \mathrm{~m}$, but was $197 \mathrm{~kW} / \mathrm{m}^{2}$ at a height of $85 \mathrm{~m}$ and only $57 \mathrm{~kW} / \mathrm{m}^{2}$ at a height of 120 $\mathrm{m}$. The trend from equivalent data recorded from the South spoke is less clear, although it also shows a variation from $160-270 \mathrm{~kW} / \mathrm{m}^{2}$.

Even though the results from the model are conservative compared to Test 2, they are significantly better than the comparison shown in red in Figure 10. This comparison was added to show the predicted radiation if it was assumed that the fire spread across the whole spill area, as recommended by Luketa [7] if there was not a physical basis for the non-burning regions. 


\section{Conclusions}

The experimental data recorded during the Phoenix LNG pool fire tests [3] has been analyzed to understand the three unexpected phenomena that were observed when compared to previous large scale LNG pools fires. An empirical and CFD study showed that the non-burning regions could be explained by an inward entrainment velocity created by thermal updraft that was sufficient to stop flames from the edge of the pool fire spreading outwards to cover the whole LNG pool [10]. At the same time, the vaporized methane fuel from the surface of the non-burning regions fed the pool fire in the center and so created a higher effective regression rate that could explain the longer pool flame length (height).

Mid-scale tests were carried out to demonstrate that the flame across a LNG pool fire could be halted by an air flow of $2.8 \mathrm{~m} / \mathrm{s}$ in the opposite direction. The resultant flame front was angled at $20-40^{\circ}$ to the air flow and the resultant entrainment velocity of approximately $2 \mathrm{~m} / \mathrm{s}$ was similar to results obtained from CFD analysis [10], [16]. Altogether the results showed that non-burning regions would start to form in open water as the fire diameter exceeded 20-30 m, although the effects of obstacles may reduce the local wind field and enable flame to be anchored and grow larger than $30 \mathrm{~m}$; as occurred during the second Phoenix test.

The effect of water vapor on reducing cold soot and hence smoke shielding was investigated using chemical kinetics. The analysis demonstrated that water from air and from the water column below the fire would reduce the soot concentration. However, the results could not be extrapolated and so it was conservatively assumed that smoke shielding would not occur.

The overall analysis was used to develop a modification to the solid flame ("integral") model that is implemented in the Shell major hazard consequence tool, FRED. By default, this model uses a $30 \mathrm{~m}$ limit for the pool fire size and adjusts the regression rate by the relative size of the spill to fire size to account for the flame length. The model was verified against experimental data from the Phoenix test series, and although conservative, gave good agreement with the experimental data and especially for Test 1 . It was postulated that the results from Test 2, may be overpredicted due to a decrease in SEP in the upper half of the flame [3], which is not considered within the model.

Further work should consider how the prevailing wind, ignition location, sea state and the potential for the flame to anchor to structures may influence the pool fire size; to improve the empirical model and provide better guidance during major hazard assessments of catastrophic leaks of LNG on water.

\section{Acknowledgements}

The author would like to thank the Shell LNG Technology platform for supporting this work over the last five years and the UK Health and Safety Laboratory (HSL) for their contributions while they were contracted to develop the CFD models and perform the mid-scale experimental testing. 


\section{References}

[1] "2017 World LNG Report” International Gas Union

http://www.igu.org/sites/default/files/103419-World_IGU_Report_no\%20crops.pdf

[2] Raj, P.K. "LNG fires: A review of experimental results, models and hazard prediction challenges" 2007, Journal of Hazardous Materials 140, 444-464

[3] Blanchat T., Helmick P., Jensen R., Luketa A., Deola R., Suo-Anttila S., Mercier J., Miller T., Ricks A., Simpson R., Demosthenous B., Tieszen S., and Hightower M. (2011). The Phoenix series large scale LNG pool fire experiments. SAND2010-8676, Sandia National Laboratories, Albuquerque, NM.

[4] Nedelka D., Moorhouse, J., and Tucker, R.F., 1990 "The Montoir 35m diameter LNG pool fire experiments", Proc. 9th Int. Conf. on LNG, Nice, 17-20 Oct. 1989, Publ. by Institute of Gas Technology, Chicago

[5] Thomas, P.H., 1963, The size of fires from natural fires, Proc. 9th Int. Symp. on Combustion, The Combustion Institute.

[6] MKOPSC (2008). Mary Kay O'Connor Process Safety Center. LNG Pool Fire Modeling. White Paper. September 2008

[7] Luketa, A. (2011). Recommendations on the Prediction of Thermal Hazard Distances from Large Liquefied Natural Gas Pool Fires on Water for Solid Flame Models. Sandia National Laboratories report, SAND2011-9415, December 2011.

[8] A. Luketa, T. Blanchat "The phoenix series large-scale methane gas burner experiments and liquid methane pool fires experiments on water" Combustion and Flame 162 (2015) 4497-4513

[9] Betteridge, S., Hoyes, J.R., Gant, S.E. and Ivings, M.J., Consequence modelling of large LNG pool fires on water, IChemE Hazards 24 Conference, Edinburgh, UK, May 2014.

[10] Atkinson, G., Betteridge, S., Hall, J., Hoyes, J.R., Gant, S., "Experimental determination of the rate of flame spread across LNG pools", IChemE Hazards 26 Conference, Edinburgh, UK, May 2016.

[11] ANSYS, 2012, ANSYS CFX-Solver Modeling Guide. ANSYS, Inc., Canonsburg, Pennsylvania, USA.Release 14.5, October 2012.

[12] Lewis, B., and von Elbe, G. (1961). Combustion, flames and explosions of gases, Second Edition. Academic Press, New York

[13] Gottuk, D.T. and White, D.A., 2002, Liquid Fuel Fires. Chapter 15, Section 2, SFPE Handbook of Fire Protection Engineering, 3rd Edition. National Fire Protection Association, Inc., Quincy, Massachusetts, USA.

[14] Burgoyne, J.H. and Roberts, A.F., 1968, The spread of flame across a liquid surface, Proc. Roy. Soc. A. 308: 55-68.

[15] Paxton, B and Dismile, P., 2013, Flame spread over liquid pools, Aviation Fire Dynamics presentation, University of Cincinnati, USA. (Available from: http://www.ase.uc.edu/ pdisimil/classnotes/Aviation\%20Fire\%20Dynamics/Reserach\%20Papers /FlameSpread_Paxton_05Apr2013.pptx, accessed 24 December 2015). 
[16] Kelsey, A., Gant, S.E., McNally, K. and Betteridge, S., 2014, Application of global sensitivity analysis to FDS simulations of large LNG fire plumes, IChemE Hazards 24 Conference, Edinburgh, UK, May 2014. (Available from:

https://www.icheme.org/ /media/Documents/Subject\%20Groups/Safety_Loss_Prevention/Hazar ds\%20Archive/XXIV/XXIV-Paper-33.pdf).

[17] Zukoski, E.E., Kubota, T. and Cetegen, B. (1981). Entrainment in fire plumes. Fire Safety Journal, 3, 107-121.

[18] Heskestad, G. (1986). Fire plume air entrainment according to two competing assumptions. 21st Symposium on Combustion, Combustion Institute, Pittsburgh, PA.

[19] Zukoski, E.E. (1995). Properties of Fire Plumes. Chapter 2, Combustion Fundamentals of Fire. Academic Press Limited, London, UK.

[20] Heskestad, G. (2002). Fire Plumes, Flame height, and Air Entrainment. Chapter 1, Section 2, SFPE Handbook of Fire Protection Engineering, 3rd Edition. National Fire Protection Association, Inc., Quincy, Massachusetts, USA.

[21] HGSYSTEM, www.hgsystem.com

[22] Babrauskas, V. Fire Technology 19 (1983) 251-56.

[23] Fengshan Liu a, Jean-Louis Consalvi b, Andrés Fuentes, Effects of water vapor addition to the air stream on soot formation and flame properties in a laminar coflow ethylene/air diffusion flame, Combustion and Flame 161 (2014) 1724-1734

[24] Cosilab software http://rotexo.com/cosilab.php

[25] GRI Mech reaction mechanism http://combustion.berkeley.edu/gri-mech/

[26] Leung, K. M., Lindstedt, R. P. and Jones, W. P. (1991). A Simplified Reaction Mechanism for Soot Formation in Nonpremixed Flame, Combust. Flame, Vol. 87, pp. 289-305.

[27] Johnson, A.D., A model for predicting thermal radiation hazards from large-scale LNG pool fires, Inst, Chem Eng. Symp. Ser., 1992, v13, p507-57 